\title{
OPERACIONES NOTABLES DE LA CIENCIA DEL DERECHO
}

\author{
Manuel María Zorrilla Ruiz \\ Catedrático de la Universidad de Deusto \\ Profesor Visitante de la Universidad de Burdeos (Francia) \\ y de la Universidad de Lodz (Polonia)
}

\section{Función y utilidad sociales de la ciencia del Derecho}

El Derecho es un producto indispensable para la estabilidad y el buen gobierno de cualquier sociedad que, como conviene a su naturaleza, se encamina a la consecución del bien común. Idea que, ante todo, se plasma en una coexistencia conflictiva y templada por el buen sentido de los ciudadanos y el adiestramiento en el respeto de los derechos ajenos. Se refleja también en cuantas acciones de colaboración se precisan para asumir ciertas cargas y soportar las oportunas responsabilidades. Consiste, además, en una participación consecuente con el derecho a beneficiarse de las adquisiciones que integran un patrimonio extensivo a cuantos forman las comunidades o grupos comprendidos en el todo del cuerpo social.

El Derecho - sustento y vestidura de la sociedad que se organiza en el Estado y que no puede soslayar las soluciones jurídicas para suavizar la rigidez de sus tensiones interiores - no se debe a una iniciativa desinteresada o platónica, sino a la decisión de las colectividades que le descubren y emplean para defender - los más pesimistas - su instinto de conversación y encauzar - los más optimistas - su proyecto de solidaridad. A medida que las declaraciones solemnes de derechos se instalan en los horizontes de la libertad, resuena, en todas ellas, el eco de esta o parecida idea. La vieja consigna revolucionaria —libertad, igualdad, fraternidad - muestra que, a impulsos de las dos primeras, el individuo escapa a las servidumbres de la tiranía y de la fuerza incontrolada, para sobrevivir como persona que - dejando definitivamente de ser súbditoestrena y exhibe con orgullo su nueva y briosa condición de ciudadano. El sentimiento de solidaridad concita y anima los esfuerzos precisos para andar los caminos que colman las ilusiones del presente y entrenan en la edificación del porvenir. El Derecho así solicitado intenta superar estos 
retos, pero, al hilo de las dificultades que registran las experiencias de sus fracasos y sus éxitos, se convierte en un problema en sí mismo. Dejando de ser un útil simplificado y manejable, se transforma en un ingenio de vastas dimensiones. Su mantenimiento debe asegurarse como el ajuste de una compleja y delicada maquinaria que no puede detenerse ni romper el ritmo regular de su marcha. De ahí emana la inquietud de un pensamiento de problemas planteados para responder a los interrogantes $\mathrm{y}$ superar las dificultades que acompañan a la producción, aplicación y conocimiento del Derecho. De ahí sólo hay un paso a la conversión del Derecho en objeto científico y a la apertura de un debate sobre el acierto de esta opción, y las propuestas que desencadena.

La distinción estética y el aprecio moral que dispensó al Derecho la sociedad romana, explican la reputación y predicamento que ganó hasta el punto de reputarse el arte de lo equitativo y de lo bueno. Del Derecho se ha dicho que, en unión de otros rasgos significativos, constituye una de las claves o expresiones fisiognómicas de la cultura occidental. Importancia que cundió a lo largo del tiempo y que, en su momento, dio lugar a que una esmerada rehabilitación científica de los materiales del Derecho romano generase una inquietud cuya excelencia de contenido y de sistema precedió al ímpetu del movimiento codificador e hizo de éste, pese al discreto crédito de las corrientes descodificadoras, un modelo imitable.

\section{Enclave de la ciencia del Derecho}

El Derecho constituye un producto científico cuyas reglas de ordenación se proponen, por encima de todo, disipar la oscuridad y combatir la anarquía expositiva. Siempre aspira a condensar sus verdades en proposiciones sencillas, comprensibles, persuasivas, útiles y armónicamente coordinadas. La suma de experiencias constitucionales y codificadoras de fe del éxito de una propensión tan doctrinalmente sugestiva como socialmente fecunda y perdurable.

Las ciencias de la naturaleza se reconocen porque, al materializarse las hipótesis prefiguradas en sus leyes, los efectos —que éstas enuncian y predicen por obra de una averiguación inductiva - sobrevienen inexorablemente, sin precisarse la interposición de una conducta humana para su producción. Todas las ciencias del espíritu —en cuyo espacio habitable reside el Derecho - se singularizan por lo insuficiente de la simple existencia y verificación del supuesto o circunstancia histórica - que sus leyes cuidan de definir caso por caso- para prever las consecuencias que no pueden surgir sin el concurso de una mediación especulativa 
que haga viable su proyecto y agote sus posibilidades de eficacia. Las normas jurídicas - leyes, en su sentido más amplio, que pueblan el mundo del Derecho- carecen de un impulso interior que les haga eficaces sin el empuje de un componente activo y exterior. Si se acatan voluntariamente, su bondad viene de la conformidad y aceptación de cuantos, dispuestos a cumplirlas, realizan pacíficamente el programa de su supuesto de hecho. Si se desobedecen o cuestionan, su solo imperio no basta para restaurar automáticamente el orden jurídico alterado por su desconocimiento o transgresión. Se requiere que una operación intelectual individualice y declare dicha necesidad, sin perjuicio de acudirse a una compulsión adicional en el caso de que esa aceptación - consiguiente a un juicio lógico y una valoración favorable de cada estado de cosas- no llegue a producirse.

Nada es tan elocuente como la equiparación de la efectiva tutela judicial al derecho fundamental de todas las personas a obtener de la jurisdicción una protección gradual de esta naturaleza (art. 24.1 CE). Ello apareja — como interposición de la voluntad declarativa de un poder del Estado - la posibilidad de conseguir una respuesta — favorable o adversa, pero siempre formalmente motivada y animada por un discurso mínimamente persuasivo y sólido - al problema de fondo que se dilucida. Comprende asimismo las operaciones conducentes a la satisfacción del interés cuya legitimidad se arguye para provocar una atención transformadora y no un aserto retórico que se detiene a mitad de camino entre lo eficaz y lo testimonial.

Así las cosas, la ciencia del Derecho no pertenece al ámbito de las ciencias exactas, ya que - a diferencia de ellas - no permite aquilatar, inequívoca y exhaustivamente, la verdad objetiva ni el acierto absoluto del discurso a que acostumbran los juristas, y de las conclusiones que establecen cuando deciden las cuestiones de su oficio y especialidad. La solución de un problema cuyo planteamiento y decisión se arreglan a las leyes de la naturaleza es única. Si su sentido se aparta o aleja de la verdadera respuesta, siempre hay medios y procedimientos - completa y no sólo relativamente fiables - para cerciorarse de la discrepancia y proceder a su denuncia. Los problemas jurídicos toleran más de una solución aceptable - que no es lo mismo que una respuesta exacta- $\mathrm{y}$, si se apuntan varios, no cabe eliminar, en nombre de una verdad comprobable categóricamente, todas menos una de las que se proponen. Siempre y cuando se muestren convincentes y sanamente razonables, cualquiera de ellas puede aspirar a que sus pretensiones de verdad perduren. Ello no impide que, pese a sus respectivas cuotas de razonabilidad, todas resulten intrínsecamente falsas a la luz de un Derecho ideal cuya elección indubitada es, las más de las veces, misión imposible. Basta que los crite- 
rios de que usa la ciencia del Derecho para resolver sus problemas, consigan persuadir, dado el peso de su autoridad dialéctica, a espíritus sanamente críticos, de la solvencia del discurso que informa una solución determinada, y de la dosis de justicia que, sin merma de sus garantías tecnicojurídicas, le asiste en esas circunstancias.

\section{Razonabilidad metodológica de la ciencia del Derecho}

La idea de razonabilidad — afín a la de posesión de cordura jurídica o, si se prefiere, de animación científica del sentido común- familiariza con la diversidad y contingencia de las opciones que forman el soporte metodológico de la ciencia del Derecho. Trasladada a las peripecias del período constituyente, quiere decir que, si la ley fundamental acumula conceptos jurídicos indeterminados o frecuenta proposiciones muy flexibles, su desarrollo legislativo admite alternativas de contenido variable, queridas por un legislador que, sin duda, las juzga enriquecedoras y valiosas. Acepta, como grandeza y servidumbre de sus previsiones, que, gracias a esa elasticidad, el Derecho constituido incorpore adquisiciones venidas de cualesquiera zonas ideológicas.

La ciencia del Derecho no sólo edifica y hace suya la metodología de la razonabilidad, sino que también descubre el acierto de su aplicación y transferencia a las acciones jurídicamente notables de los poderes públicos. He ahí un auxilio de primera magnitud para facilitar, en lo que respectivamente tiene de autolimitación y garantía, la sujeción de los ciudadanos —en cuanto propiamente tales, administrados y justiciables- al ordenamiento jurídico.

La razonabilidad se predica de la legislación ordinaria, porque, como se ha dicho, el decisionismo político - inseparable, por naturaleza, de esta potestad e inspirado en el valor superior del pluralismo que guía sus manifestaciones (art. 1.1 CE) — autoriza y fomenta distintas lecturas aceptables de un mismo pasaje constitucional, e invita a su despliegue de acuerdo con criterios que - aun cuando incompatibles con otros de ideología divergente y no, por ello, menos constitucionales - traslucen, como no puede menos de ocurrir, las pautas de su credo ideológico. Aplicada a la actividad ejecutiva, la razonabilidad se condice con la prescripción del pleno sometimiento de sus titulares a la ley y al Derecho (art. 103.1 CE), y se completa con la consigna de adecuar esas acciones a los fines que las justifican, a causa de una discrecionalidad cuyo presumible acierto les hace jurídicamente respetables (art. 106.1 CE). El ejercicio de la jurisdicción es razonable si los actos judiciales de aplicación del Derecho se impregnan de un tanto de sugestión intelectual bastante 
para que, sin perjuicio de otras interpretaciones concurrentes, se les conciba como decisiones cuyo tino está respaldado por la conformidad social. Verificar, desde un punto de vista constitucional, la efectividad de la tutela judicial no es subrogarse, para controlar el acierto intrínseco de sus criterios tecnicojurídicos, en la postura del juez ordinario que ha de resolver. No es convencerse — apurando las referencias críticas- del acierto de los argumentos que avalan sus pronunciamientos, salvo si encierran juicios o conclusiones aberrantes que necesitan corrección. Es, menos crudamente, cerciorarse de si hay un esfuerzo razonador y discursivo que — siquiera expuesto a error, como cualquier acción falible y aún más las de las ciencias del espíritu- defiende y asegura, sin turbación intelectual ni repugnancia moral, la solución que fluye de una aplicación natural — no violentada- de las normas de Derecho objetivo.

\section{Pretensión ordenadora y armónica de la ciencia del Derecho}

La ciencia es merecedora de este nombre si, gracias a su calidad metodológica, supera la pobreza de la impresión causada por un alud de datos inconexos, viciosamente acumulados y constatados de modo incompleto, tal y como de antiguo se han ocupado de ellos los saberes rudimentarios o acientíficos. La ciencia debe constatar el acervo de verdades en que se mira su curiosidad, cualquiera que sea su magnitud histórica, social o económica. Ha de configurarlas con la pulcritud y aprecio necesarios para dar con éxito los primeros pasos del conocimiento científico y fijar, sin yerros, las constantes con que se dispone a operar.

La ciencia encara tales situaciones y determina la medida en que su interrelación o sus puntos de conexión obedecen a reglas que, una vez descubiertas y reducidas a proposiciones comprensibles, engrosan el haz de las verdades provechosas - en cuanto indispensables para alcanzar sus fines - de la parte del saber a que afectan. La ciencia agrupa sus verdades en un todo sistemático que, como se dijo de lo bello, complace a la razón y la convence, pues las presenta de forma equilibrada y reñida con las tentaciones de desorden, cómodamente perceptible - de ahí la excelencia del efecto mayeútico o recompensa del esfuerzo que abre paso a la verdad científica- e intelectualmente sugestiva, pues el proceso de hallazgo y formulación de la verdad despierta reacciones de devoción y elogio.

La tarea de sistematización o puesta regular de cada cosa en el lugar o espacio que le corresponde, conviene a todo hacer científico que, preciándose de tal, persigue el progreso de su conocimiento y el éxito de su investigación. El Derecho — más que cualquier otra ciencia - alimen- 
ta sus operaciones científicas del propósito y el tono sistemáticos que indefectiblemente le acompañan. Una de las adquisiciones —que, culminando el éxito del positivismo legalista, quiso liquidar, sin fortuna, la querencia por el retorno incesante del orden natural- del espíritu armónico y universal, fue el triunfo de las ideas codificadoras que, al precio del valor sistemático de sus ensayos, dieron por inmejorable un Derecho cuya excelente calidad provenía del esfuerzo ingente de coordinación y puesta en orden — con presencia coordinada, armoniosa y útil- de los materiales elegidos entonces. Proscribía, por innecesariamente perfeccionista y socialmente superabundante, la pretensión de controlar sus normas en nombre de la justicia material y de ir más allá de un tratamiento que, de una vez por todas, depurase la calidad óptima de aquéllas.

El Derecho ha ejercitado siempre una aspiración ordenadora interna y externa. Se ha propuesto racionalizar eficazmente la vida social mediante normas que, en lo posible, se señalan por su adecuación a los ideales de justicia y que no obedecen a la voluntad pura y dura, por dominante y/o temible que parezca, de quienes encarnan y/o ejercen el poder. Pese al énfasis que reitera la autosuficiencia de la positividad del Derecho objetivo y apela a la legitimación conferida por el sistema de normas propias del ordenamiento jurídico que le corresponde, no es posible rehuir las referencias que - con más o menos vehemencia o entusiasmo, pero nunca casual o inadvertidamente- hace el legislador a valores de base metafísica o conexos con los atributos de la dignidad del ser personal. Esta actitud de sensibilidad moral puede exigir, por excepción, una interpretación directamente asociada, a esas esencias moralizadoras (art. 1.1 CE). Así ocurre, porque todo sistema pone orden y armonía allí donde su vigor constructivo coopera a que la verdad científica brille con luz propia y no decaiga en su esplendor. La defensa del orden natural — de cuya integridad formaba parte el universo de las cosas y de las causas justas- había alcanzado un grado de perfección insuperable y se regía por un depósito de leyes llamadas, a causa de ello, naturales y orquestadas por un fondo de música celestial.

A la perseverancia y suficiencia del entendimiento humano incumbía — tratándose del Derecho- descubrir y mecanizar la vida de las normas rectoras de sus instituciones, porque sólo un ejercicio de persecución gradual y laboriosa permitía escrutarlas minuciosamente y agotar la riqueza de sus derivaciones.

Además de lograr los objetivos de regulación exterior y trato ordenado de la vida social, el Derecho reacondiciona, sin tregua, sus propios materiales y responde al reto diario de su cualidad de disciplina constructiva por esencia y sistemática por excelencia. El Derecho es más igual a sí mismo — activando el proceso de perfectivo de su identidad- 
y deviene tanto más eficaz, cuanto más accesiblemente se conocen y aplican sus normas, dado el nivel de madurez que alcanza el sistema de que forman parte. Las ciencias de la naturaleza son disciplinas cuyo aserto dogmático de las verdades propias no puede discutirse, si el efecto de la aplicación de sus leyes se ve avalado por la irrefutable comprobación de su certeza. Las ciencias del espíritu son — no huelga repetirlo- polémicas y relativizadas, porque sus opciones cognoscitivas toleran la razonabilidad de varias soluciones - una sola de las cuales es, a lo sumo, cierta, pero incomprobable - o porque insinúan un principio de escepticismo sobre la certidumbre de que, con todo y eso, la clave de la verdad está en alguna de las propuestas razonables que alternativamente se sugieren. La ida en pos de dicha solución se ve, en la práctica, forzada por la prohibición -impuesta a los órganos jurisdiccionales - de abstenerse de fallar si la norma jurídica calla o es ininteligible o incompleta (art. 1. C.c).

Influye en ello, sobre todo, la distinta rigidez de los respectivos mecanismos causales. El de las normas del mundo ontológico presupone el juego de una causa única, eficiente, inmediata e identificada con la producción del hecho físico que la desencadena. El de las normas deontológicas viene del concurso de dos causas eficientes, una de las cuales es mediata y la otra - constituida por el acatamiento del mandato o la prohibición, o por la declaración, comúnmente judicial, de su eficaciaactúa de modo inmediato. El rigor del primero de ambos procesos causales exige soluciones cuya justicia coincide con el respeto a la verdad objetiva - una y única - a que da lugar su aplicación. La flexibilidad o, cuando menos, la variedad de alternativas que el segundo tolera, obliga a conformarse con el beneficio de las soluciones razonables. La razonabilidad se señala por la ausencia de carácter descabellado o aberrante de la solución obtenida, por la posibilidad de trabar, sin violencia lógica ni arbitrariedad, argumentos de sólida apariencia, por la buena acogida social de la tesis propuesta y por la persuasión del discurso con que se defiende su línea de fuerza.

La perfectibilidad de las soluciones razonables resalta con ocasión del juego del principio de igualdad en la aplicación de la ley, corolario de la norma fundamental que proclama el derecho fundamental a la igualdad (art. $14 \mathrm{CE}$ ). La interdicción de la arbitrariedad de los poderes públicos (art. 9.3 CE) y la sumisión exclusiva de los jueces y tribunales al imperio de la carta política y de la legalidad ordinaria (arts. 117.1 CE y 1.1 LOPJ), justifican la vinculación de los órganos jurisdiccionales a la doctrina ya fijada en anteriores decisiones de la misma o análoga cuestión. Interviene, guardadas las distancias, una regla afín a la prohibición - típica de las situaciones de Derecho Privado- de ir contra los propios actos y violar los deberes de lealtad y corrección judiciales que, como 
expresión de buena fe (arts. 7.1 C.c. y 11.3 LOPJ), obligan a los jueces ordinarios frente a los usuarios de las normas de Derecho objetivo. No puede desautorizarse una apariencia que ha venido fundando la confianza en la realidad que pregona o la sujeción al precedente de otros sistemas jurídicos. El criterio que entonces prevalece y se acata no tiene por qué petrificarse si, al cabo de algún tiempo, sobreviene una reflexión cuya excelencia convincente prevalece sobre la menor razonabilidad de la que precede. Ello ocurre porque así conviene al ciclo de maduración de las opciones peculiares de la aplicación del Derecho. La orientación adoptada inicialmente se presume acertada, y el juez — privado de razones de peso para abandonarla y apartarse de ella - debe atenerse a un parecer que hasta el momento no ha sido desvirtuado de raíz, ni corre el riesgo de verse desplazado por otro más contundente y plausible. Tan pronto como el juez se cerciora de la existencia de un discurso más valioso y rico en argumentos que el que ha determinado su vinculación al precedente, deja de estar justificada la sujeción a su doctrina y se disipa el fundamento de la adhesión — que se reforma- a la tesis jurídica de origen.

\section{Preferencia sistemática de la ciencia del Derecho}

La influencia de lo sistemático en la construcción de la ciencia del Derecho tiene manifestaciones muy notables. Pese a pertenecer al campo de las ciencias del espíritu y disponer de un margen de amplitud constructiva, los peligros de errar en sus juicios obligan a multiplicar un esfuerzo de rigor y precisión que otras disciplinas de su mismo medio no exigen o sustituyen, sin mayores reparos, por el recurso a la simulación o el arbitrismo. El método cobra máxima importancia en el estudio del Derecho, a causa de la inexcusabilidad de su empleo para definir lo que el Derecho es, como realidad ontológica, y conocer lo que significa, como respuesta a la grandeza de su desafío finalista. El Derecho - que, por fortuna para la causa de la sociedad y la persona, no es una ciencia exacta— llegó a auxiliarse de las disciplinas matemáticas cuando la especulación racionalista y la expansión de su yusnaturalismo secular sostuvieron que, desde esa zona de severo conocimiento científico, se cooperaba eficazmente al hallazgo y depuración de las verdades jurídicas. Tal vez las averiguaciones genéticas expliquen algún día por qué en un linaje familiar de juristas notables conviven distinguidos cultivadores matemáticos. La aportación de la informática al Derecho, enriquecido con su contribución, muestra lo incierto y discutible de su vertiente oscura o propensión a sustituir — como un legado más de la inteligencia artificial y de las servidumbres que sus 
especialistas trivializan o disimulan afanosamente - lo que la ciencia jurídica encierra de particularismo creativo.

Gracias a la estima y el uso de lo sistemático, el dogmatismo jurídico no es un acopio unilateral e intransigente de verdades, sino la asimilación de la capacidad de revisar un acervo de soluciones razonables y sometidas a los controles de la crítica.

La dogmática jurídica es la oferta doctrinal o científica del Derecho a través de una propuesta más o menos vasta y complicada. Ello aumenta las oportunidades de ventilar los problemas derivados del funcionamiento de una institución jurídica o a la emergencia de ciertos fenómenos que, imprimiendo carácter al mundo del Derecho, predisponen a análisis enriquecedores del patrimonio pensante del sistema y aseguran el equilibrio armónico de sus elementos. La técnica jurídica es la suma de criterios que las soluciones dogmáticas adoptan y difunden para realizar actos singulares de aplicación del Derecho.

La delicadeza de la construcción sistemática se agudiza y agrava cuando actúa sobre el depósito de seguridad y de certeza que procura el acervo del Derecho constituido. Tiene que ser más cuidadosa, porque su acierto queda puesto a prueba cuando se suscitan dificultades de aplicación de las normas jurídicas afectadas por la configuración y el dinamismo del sistema al que pertenecen. Trátase, en suma, de un ejercicio de responsabilidad. Su función puede relativizarse u ofrecer soluciones alternativas que, desbordando los confines de la dogmática jurídica, se internan en los pagos de la consideración filosófica del Derecho y los invaden para explotar sus yacimientos. Ello no excluye lo sugestivo y, a la vez, dramático de una mayor libertad especulativa que, a cambio de la movilidad del discurso, se sensibiliza a problemas de gran envergadura y los reconstituye de raíz. Cuestión que se aborda más saludablemente a la luz de las soluciones de un Derecho Positivo que, aunque acorta el vuelo de su pensamiento, multiplica su eficacia y permite fijar el óptimo de sus posibilidades. Nadie, por citar un supuesto vigente, niega la importancia de un atinado planteamiento del régimen de la guerra justa, siempre y cuando quepa revivir este tema, ni deja de lamentar la ausencia de textos, aún rudimentarios, en que apoyar su reconstrucción y actualización doctrinales.

\section{Expresiones sistemáticas de la ciencia del Derecho}

El Derecho es infiel y deja de servir a sus fines, si pierde de vista que los requerimientos de la dogmática jurídica se cumplen mediante operaciones de definición, tipificación y calificación. Tres especies concatena- 
das y simultáneamente imprescindibles para que la dogmática satisfaga esos fines.

Definir es describir y delimitar una institución a través de los rasgos que la configuran inequívocamente y la distinguen de otras a las que se asemeja o con las cuales puede confundirse. Toda definición provee insustituiblemente a este designio de identificación. También sirve para completar las operaciones interpretativas, si hay que acudir al contexto de las normas jurídicas - parte integrante de esas definiciones-que las hace comprensibles en el caso de oscuridad o ininteligibilidad de sus proposiciones (art. 3.1 C.c.).

Tipificar —expresión acaparada por el Derecho Penal para reseñar las conductas punibles, aunque es legítima e incluso aconsejable su traslación conceptual a otros sectores del ordenamiento jurídico que la utilizan provechosamente - es referir alguna de las situaciones o episodios a cuya constancia subordina la norma jurídica la producción de los efectos que de su mensaje se derivan. Suele asignarse a esa norma una estructura que comprende la descripción, en clave condicional, del acaecimiento hipotético - propuesto por el legislador-y la predicción de las consecuencias que deben - he aquí el impacto deontológico- aceptarse voluntariamente o sobrevenir cuando dicho suceso acaece. Se dice que deben producirse y no que se producen, porque al contrario del mundo del ser, regido por leyes de juego inexorable y automático, el mundo del valor — del cual es parte la ciencia del Derecho- se somete a normas cuyo mecanismo no entra en juego sin el concurso impulsivo de una voluntad que asiente al mandato o la prohibición ahí formulados, o que destruye la oposición de cuantos se resisten a cumplirlos. Lo más frecuente es que las tipificaciones se ordenen, sistemáticamente y faciliten la operación de subsunción, que compara el dato histórico con la descripción abstracta de la norma, determinando si encaja en ella sin holguras, o si, al contrario, su adecuación exacta se ha frustrado. El trabajo de tipificación y declaración de los efectos fue propio del llamado, con alguna simplicidad, silogismo judicial, donde el legislador escribía, en el cuerpo de la norma jurídica, la premisa mayor -omnicomprensiva y general-y, a su vez, el juez aportaba la premisa menor - de signo discursivo y dependiente de la comprobación y complejidad de los hechos- y formulaba, en fin, la conclusión. Apreciaba si se daba el estado de cosas objeto de concreción legislativa y, en función de ello, declaraba las consecuencias pertinentes.

Las instituciones deben someterse a una esmerada disección para extraer los rasgos que las identifican y vaciarlas en moldes cuya aplicación facilita su análisis exhaustivo. Las clasificaciones de las ciencias de la naturaleza agotan su utilidad en sí mismas y no llevan su eficacia más 
allá de lo que representan. Las calificaciones del Derecho son, en cambio, de máximo provecho y cumplen una notable función de diagnóstico. El análisis de una institución comprende los extremos relativos a su $n a$ turaleza jurídica y la explicación de lo que significa a la luz de instituciones o categorías preexistentes y con las que se está familiarizado. Los problemas de una institución nueva son, a veces, los de instituciones ya conocidas que sirven para caracterizarla. Así sucede cuando el concepto de relación jurídica no sólo se refiere al tratamiento de los modelos de Derecho Privado, que fueron emblemáticos para perfilarla, sino también de otros ejemplos que utilizan su contribución. El proceso judicial se ha explicado como una relación jurídica entre los litigantes - gravados con la carga de las alegaciones y la prueba- y el órgano jurisdiccional cuya respuesta dilucida la cuestión de fondo debatida. La atención de los servicios públicos se configura al modo de una relación jurídica entre las Administraciones Públicas, que los prestan, y los administrados que, reuniendo ciertas condiciones, tienen acceso a ellos. El mecanismo de sostenimiento de las cargas públicas se explica por medio de una relación tributaria que se constituye entre el Fisco y las personas afectadas por la obligación de contribuir, a cambio de ciertas atenciones de interés general. El legislador tiene, en cuenta, no pocas veces, la afinidad de naturaleza jurídica entre las instituciones jurídicas y aplica a las más novedosas todo o parte del régimen de las ya sabidas (arts. 185 y 406 C.c.).

\section{Intervención analítica de la ciencia del Derecho}

La ciencia del Derecho discurre, cualquiera que sea la suerte de sus operaciones, sobre el tejido de las normas que ocupan las varias parcelas o sectores del ordenamiento jurídico. Reglas concebidas y enunciadas en un lenguaje que describe conductas del individuo o de las colectividades, y que atribuye a su realización unos efectos reguladores del orden social. La idea de conducta se entiende en el más amplio sentido, pues, aunque las proposiciones normativas encierran juicios comúnmente descriptivos de acciones u omisiones del sujeto que se considera, no faltan ocasiones en que sustituyen la iniciativa personal por la intervención de los acaecimientos físicos o sociales cuyos resultados han previsto.

Otras ciencias detienen su atención en comportamientos reales y emplean la inducción experimental para fijar las reglas que, determinándolas y explicando sus pormenores y tendencias, arrojan luz sobre sus contenidos. Los moralistas - que reparan en las conductas individuales o en las aspiraciones colectivas de un momento concreto- empiezan por hacer historia e inventario de las situaciones que las acreditan, pero no pue- 
den omitir una elaboración que, usando de métodos fiables, complete el diseño de las líneas de fuerza o directrices del universo ético al que dedican su atención. Un sociólogo tiene, que sistematizar las acciones y reacciones de los grupos sociales que estudia e intentar — si entiende que ello conviene a su conocimiento científico y que su método debe ir más lejos de esas verificaciones - reducir a fórmulas inteligibles y efectivas los postulados a que parecen responder.

La ciencia del Derecho interviene más morosamente ante la necesidad de que su objeto se preconstituya - como tema de crítica- gracias a la acción normativa de los poderes públicos (arts. 66.2 y $97 \mathrm{CE}$ ) y al trabajo de la jurisprudencia que ejerce su censura doctrinal (arts. 24.1 y 117.1 CE). No examina y selecciona las conductas humanas para graduar la notabilidad o conmoción de su impacto social y crear las normas jurídicas que van a regularlas. Tal objetivo es propio de otra disciplina, cuyos expertos se conducen a imitación de los moralistas y sociólogos que destilan las reglas respectivas de que se ha hecho mención; a saber, de la ciencia de la legislación o política legislativa. La contraposición y las diferencias que median entre la ciencia del Derecho y la ciencia de la legislación son, a la vez, causa y efecto de la distancia que separa un Derecho centralista de juristas - prestos a la coartada voluntarista de la oportunidad política y a la obsequiosa satisfacción de las predilecciones y apetencias del poder establecido- y un Derecho periférico de profesores, políticamente neutral y dedicado a la reconsideración y denuncia crítica del primero. La ciencia del Derecho no desiste de influir en la ciencia de la legislación o, por mejor decir, en una variante de la misma que, a causa de los orígenes que le individualizan, no siempre acata y respeta con escrúpulo el método a seguir y enarbola varas de medir muy distintas para su elección. La ciencia del Derecho es teoría general del Derecho en cuanto que atiende a los problemas de la morfología y perfección sistemática de las normas jurídicas, e incluso pone su complacencia -elogiando su factura y estilo- en la contemplación estética de las proposiciones normativas a cuyo examen se dedica. Es ciencia de Derecho porque aplica el óptimo de su espíritu crítico a mejorar la calidad de las normas de un determinado sistema estatal de Derecho Positivo.

\section{Objeto del análisis de la ciencia del Derecho}

Las proposiciones normativas, contenidas en cada sector del ordenamiento jurídico, declaran los efectos anejos a supuestos de hecho que no se seleccionan ni definen precipitada o arbitrariamente, pues el acierto de su introducción depende de predecir, sin error grave, la probabilidad o 
frecuencia con que esas situaciones van a darse, y de la dimensión — de amplitud e intensidad variables - que adquieren en la comunidad portadora del interés cuya tutela se desea. La simple posibilidad -física y lógica - de que dichos supuestos acaezcan — cuando no hay una fiable predicción de su frecuencia o impacto social, o de su extensión a un número significativo de personas- privan del carácter de proposición normativa al juicio que entonces se emite, sin necesidad probada ni utilidad general para el círculo de destinatarios a que el mandato o la prohibición van dirigidos.

El legislador puede incurrir en estas deficiencias - pocas veces irreflexivas o impremeditadas y casi siempre fruto de alianzas políticas o consignas impuestas - y la ciencia del Derecho debe denunciar lo escasamente edificante de aceptarlas con resignación y renunciar a combatirlas.

Las proposiciones normativas prescriben conductas que el sujeto debe ejecutar, si se está ante un mandato, u omitir, si se trata de una prohibición, o describen acaecimientos que, con independencia de la voluntad e iniciativa de las personas y grupos sociales, dispensan de las acciones u omisiones requeridas para que se dé un cierto efecto relativo a su esfera de derechos. Determinados hechos de la naturaleza - propios de algunos modos de adquirir (arts. 366 a 374 C.c.) - o circunstancias que afectan a la existencia física de las personas (arts. 29 y ss. C.c.), corresponden a esta segunda variedad. Tales proposiciones no son aseveraciones de hecho o enunciados históricos que indican cómo los fenómenos están ocurriendo, sino juicios de Derecho que anuncian cómo, en su caso, las cosas deben ser. Se auguran así las consecuencias que de un supuesto dado van a dimanar, no de modo automático y sí en virtud de la voluntad humana que las quiere y actúa — si el Derecho objetivo prospera con el acatamiento de sus destinatarios - o las impone a medio de la coerción estatal. Toda norma jurídica tiene un supuesto de hecho que no figura en una proposición principal narrativa, sino en otra hipotética o condicional, cuyo tenor o fórmula requiere averiguar, gracias a la experiencia, cómo suceden los acontecimientos o se perfeccionan las conductas que el legislador valora y selecciona para incorporarlas a dicho pasaje. Los efectos que la posesión - en que confluyen perspectivas y situaciones de hecho y de Derecho - trae consigo, son incomprensibles sin un conocimiento sensorial acertado y una fidedigna representación intelectual de las distintas experiencias posesorias (arts. 430 a 433 C.c.). La parquedad del amor al oficio en el arte de legislar explica los defectos que, a causa de la compleja o ininteligible formulación del supuesto de hecho, entorpecen la posibilidad de representarse, con lucidez y exactitud, el acaecimiento o suma de sucesos integrantes de aquellas situaciones cuya importancia requiere que el Derecho objetivo repare en su im- 
portancia y se ocupe, para regularlas, de sus vicisitudes. Las normas pueden autoabolirse si, ya de entrada, hay dificultades para interpretarlas conforme al sentido propio - ¿distinto del significado literal? - de las palabras cuyo encadenamiento constituye los juicios integrantes de sus proposiciones (art. 3.1 C.c.), pues ello impide recrear el estado de cosas para cuyo remedio fueron dadas. Toda norma jurídica ordena y encauza las conductas — de ahí su denominación — a partir de las verificaciones y experiencias que justifican su advenimiento - generalizador y razonable- al ámbito del Derecho objetivo. Tan importante es este conocimiento empírico, que la aplicación analógica de las normas jurídicas parte de una similitud o identidad de razón (art. 4.1 C.c.) - a saber, la existente entre el caso regulado y el afectado por la laguna que debe colmarse- que sólo se aprecia si el sujeto integrador no yerra al comparar las experiencias sensibles que contempla. La utilización de los medios de prueba necesarios para defender el derecho de las partes (art. 24.2 CE) satisface el derecho y la carga de acreditar los extremos fijados en el supuesto de hecho de una norma jurídica, cuando su realidad coincide con la resultante de reconstruir las comportamientos o episodios que ha tenido a bien representarse.

\section{Significado y valor de la dogmática jurídica}

La necesidad y el progreso de la ciencia del Derecho se justifican por la insuficiencia de la acción y el material legislativos para lograr que las normas jurídicas, dictadas en el ejercicio de esa potestad (art. 66.1 CE), se apliquen pacíficamente, sin divergencias ni reparos sobre su alcance, a las situaciones cuya tutela depende de la eficacia de su imperio. La dogmática jurídica — que sistematiza y sitúa el Derecho objetivo en un marco, a la vez, preciso y persuasivo- propone la doctrina que, aspirando a hacer de las leyes instrumentos de óptimo resultado social, las purgue, si hace falta, de los vicios de origen que aquejan al prestigio y el feliz resultado de sus soluciones. La cantidad y calidad de los problemas derivados de este desafío científico son impredecibles y crecen a medida que la naturaleza de las cosas, las demandas sociales y la emergencia de necesidades sucesivas recaban una intervención más intensa y frecuente del Derecho. Acción cuyos efectos no se dan de modo inmediato y automático, sino que sobrevienen con la ayuda de los instrumentos jurídicos al uso y con el inapreciable auxilio de la ciencia del Derecho que los remoza y/o adapta a las respectivas situaciones. La ley es un producto cuya dosis de voluntarismo o ingrediente de carga política, acusa deficiencias que la vician desde su nacimiento o aparecen después, porque el legisla- 
dor - sujeto paciente de los apremios de ese compromiso- se desentendió de su calidad y no cuidó de conjurar algunos de los inconvenientes que su futura suerte hacía temer. Sorprende y desalienta, a un mismo tiempo, oír de boca de ciertos responsables políticos — que acreditan la más contradictoria condición de lo que los políticos responsables deben ser- la afirmación — hecha en términos críticos- de que los debates parlamentarios se entorpecen por culpa de las reflexiones doctrinales que, a nombre de la ciencia del Derecho, se suscitan con motivo de la elaboración de las leyes. Parece más exacto que esta contribución, lejos de merecer reproche alguno, cuente como uno de los valores eminentes del proceso legislativo que injustamente se censura. Así se explica que los científicos del Derecho - comprometidos con cuanto favorezca la eficacia duradera de las leyes cuya satisfactoria aplicación se buscadenuncien los reparos de las normas jurídicas y procuren mantenerlas a punto desde sus orígenes. Corrigen deficiencias que se aprecian en el momento de su promulgación - lo cual permite actuar de modo preventivo- o resultan del contacto con las realidades de la vida y de los conflictos de intereses (p. 10 EMTPC.c) cuya génesis y evolución descubren esas anomalías e invitan a salvarlas.

El auxilio de la dogmática jurídica —en cuanto estudio sistemático de la legalidad vigente y tentativa de reducir sus contenidos al máximo de verdad posible que sus proposiciones admiten- es imprescindible para modernizar el mensaje de las leyes cuyas deficiencias obedecen a motivos varios. La ley es parte del orden positivo que, si bien aspira al óptimo de perfección que quiere ofrecer a sus destinatarios, no siempre coincide con la verdad del orden ideal o natural -inescrutable y/o inaprehensibleque lo garantiza, pero respecto al cual — carente de un depósito accesible y terminantemente formulado - no es dable medir las distancias ni enunciar todas las divergencias que originan este alejamiento.

Ello no obstante, hay una cierta sensibilidad que permite intuir el tanto de proximidad o adecuación de las normas positivas escritas a los principios del orden natural más evidentes y de mayor compulsión existencial. Los defectos de la legalidad también derivan del apresuramiento del proceso de elaboración que no siempre favorece la dignidad del estilo literario, el rigor del lenguaje tecnicojurídico y la impecable utilización de los conceptos. No es necesario un gran esfuerzo para localizar, en pasajes legislativos notables, giros y expresiones cuyo empleo debe sonrojar a los responsables de su penetración y, no menos, a quienes los toleran con harta mansedumbre (art. 84.II ET). Los agentes políticos que participan en la factura de las leyes se defienden de estas acusaciones y sostienen que el exceso de especulación hipoteca, con el inconveniente de su rigidez y prejuicios dogmáticos, la libertad de decisión y el margen de voluntaris- 
mo normativo que las operaciones de desarrollo legislativo requieren. La de todos conocida y vieja distinción entre un Derecho de juristas - que, sin agredir de frente a los intereses generales, no vela su predilección por atenerse a las consignas de la voluntad política que, al desatenderlos y orillarlos, hacen tabla rasa de sus exigencias- y un Derecho de profesores - convertido en instancia crítica de las iniciativas del legisladorrevive con especial intensidad. No siempre se cohonestan los objetivos dogmáticos de generalidad y eficiencia de la legislación con los accidentes transaccionales y pactistas que, durante el ciclo parlamentario de producción normativa, se erigen en un sensible impedimento para acceder al disfrute natural de los bienes jurídicos que así se garantizan.

Cierto que las leyes viciadas de estos inconvenientes se someten a la acción catártica de la interpretación —a la que, en ocasiones, dedica el legislador pautas o preceptos, abiertos y dúctiles, de orientación hermenéutica (p. 13 EMTPC.c.) - y de la corrección judiciales. Ello no impide y sí aconseja que la ciencia del Derecho intervenga para que, evitando situaciones polémicas, se elimine o aminore un peligro del que ya está avisando el análisis insinuado por esa lectura inmediata.

\section{Rehabilitación normativa de los sectores del ordenamiento jurídico}

El difícil entendimiento de las leyes puede deberse a una síntesis desafortunada o una incorporación precipitada y arrítmica de las aportaciones que, en el trámite parlamentario, constituyen las propuestas hechas por medio de enmiendas formales o pactos atípicos $\mathrm{y}$, a veces, mecanicistamente yuxtapuestas, sin los ajustes necesarios para evitar contradicciones o antinomias insalvables, y no devaluar las líneas de fuerza de la norma en elaboración. La mención de los trabajos preparatorios, como elemento interpretativo de las leyes (art. 3.1 C.c.), es una llamada de atención o petición de auxilio a los juristas teóricos que predicen la solución legalizada y ofrecen fórmulas para desarrollarla. La ciencia del Derecho, que contempla el fenómeno y reflexiona críticamente sobre sus episodios, favorece un aceptable rodaje de las leyes cuyos inconvenientes elimina con sus advertencias.

La ciencia del Derecho también se encarga de regenerar las normas jurídicas que, en vez de transmitir a sus destinatarios una meridiana y sincera información sobre los designios del legislador, adolecen - no por azar - de una equivocidad o confusión que oculta el propósito de escatimar — brindándole con exceso de dosificación o mezquindad- el bien 
jurídico que se defiende, y aun de interceptar — con algunos escollosel camino que ha de recorrerse para lograr su protección. Parecido es el caso de las leyes que, imponiendo a sus destinatarios determinadas cargas, erigen obstáculos excesivos y/o difícilmente superables con un esfuerzo que, en esas circunstancias, no se está en aptitud ni disposición de realizar, porque entraña sacrificios heroicos o desproporcionados. La ciencia del Derecho pretende, así las cosas, alzar el velo y descubrir - con fines preventivos - el verdadero rostro de una acción viciada de desinformación - ¿ausencia de lealtad y corrección legislativas?que, en el peor de los casos, atenta contra la buena fe y, en el mejor de ellos, denota una imprevisión poco prudente.

La ciencia del Derecho denuncia el defecto de las leyes privadas de una nota de generalidad que es, cada vez, más fácil de eludir y conculcar impunemente. No puede renunciarse a señalar la aparición de este vicio y de unos efectos potenciados por el abuso de la consideración de ley formal y, como tal, omnipotente, que concurre en toda norma jurídica cuya generalidad no se cuestiona. Sin ignorar la dificultad técnica o, si se prefiere, la imposibilidad de impugnar las leyes ayunas de esa cualidad, es elocuente y decisiva - a causa del peso moral de su censura sobre la actitud y/o la mala conciencia del legislador, y de las expectativas del interés colectivo de la comunidad de juristas - la energía crítica con que la ciencia del Derecho se apresura a denunciar lo inadmisible de semejante privilegio. Cierto que las leyes de una sociedad pluralista (art. 20.3 CE) son generales si su promulgación descansa en la necesidad de proteger los intereses así adjetivados, de que son portadores los círculos de destinatarios integrados en la máxima comunidad — que es el Estado- o en las comunidades intermedias que forman el todo de la sociedad o Estado-comunidad, modelado, a su vez, en el troquel del Estado-ordenamiento o aparato organizador. No hay cauces absolutamente eficaces para controlar el ejercicio abusivo de la soberanía parlamentaria y paliar los excesos en que incurre cuando, desfigurando la fisonomía de algunos intereses generales y subvirtiendo los valores anejos a la noción de bien común, asigna a ciertos intereses particulares una generalidad de que carecen. Intereses animados por móviles —no inconfesables, dado lo instintivo y fácil de su exhumación y diagnóstico, pero a menudo merecedores de reproche- cuya noticia no es bastante, si la voluntad política se obstina en respaldarlos, para disuadir, en nombre del sentimiento colectivo de moralidad, de la iniciativa de protegerlos irrazonablemente. A la ciencia del Derecho compete denunciar ese vicio, no sólo para cuidar de la ética legislativa, sino también para dejar a salvo la exigencia tecnicojurídica de generalidad de las leyes. Atributo negado 
cuantas veces se acude al expediente de las denominadas leyes de caso único, rótulo que, relacionado con el concepto de ley, adolece de una contradicción en los términos, pues, por definición, la ley se da para ordenar situaciones futuras, previsiblemente masivas - según un cálculo estadístico de proliferación- y susceptibles de multiplicarse durante la prolongada existencia que se augura a la norma jurídica en que su voluntad se manifiesta.

Las leyes contienen conceptos jurídicos indeterminados, cuyas menciones eran infrecuentes y se referían a aspectos de moralidad relacionados con las normas de Derecho objetivo cuya aplicación se discutía. Las nociones de equidad (art. 3.2 C.c.), de fraude de ley (art. 6.4 C.c.) y de abuso del Derecho (art. 3.1 C.c.) cumplen buena parte de su finalidad. Los jueces no llegan a concretar cómodamente estos conceptos, si antes no cuentan con el auxilio de la ciencia del Derecho que facilita y acondiciona su recepción. Propenden inclusive a instrumentalizarlos sanamente, cuando los invocan y aplican, no con ligereza, pero sí prescindiendo de un detenido análisis —obstado acaso por las prisas- que desvanezca toda duda sobre su delimitación e identidad. Hay que informar de la novedad en que consisten, dar cuenta de los antecedentes que los definen en otros ordenamientos jurídicos, reseñar los beneficios deparados por su utilización y no disimular los problemas que su acogida y aplicación engendran. La ciencia del Derecho es deudora de unas aportaciones destinadas a que el juez consiga el soporte y reaccione con la seguridad y el aplomo que muy improbablemente le acompañarían si no contase con tales asistencias.

Esto no es todo. Las leyes recogen, con frecuencia creciente, conceptos indeterminados que extravagan del campo del Derecho y pertenecen a disciplinas complementarias o auxiliares. La ciencia del Derecho cumple una función de transmisión o de tamiz que aminora las dificultades de la concreción pendiente o señala los límites dentro de los cuales el problema surge y debe resolverse aplicando esas reglas de juego.

Las leyes no escapan al inconveniente de las contradicciones o antinomias que las aquejan y que hay que disipar. El legislador introduce un germen de desorden social y vacilación jurídica, si — sin propósito derogatorio expreso o tácito (art. 2.2 C.c.) - muestra una voluntad incompatible con otra que antes ha manifestado y da lugar a resultados que no pueden ser y dejar de ser, al mismo tiempo, en su ámbito de aplicación. La ciencia del Derecho se ve obligada a disolver las contradicciones más ruidosas (arts. 759 y 799 C.c.), ya que sus soluciones, lejos de ponerse en tela de juicio, gratifican y animan a los juristas prácticos que se benefician de su esclarecimiento. 


\section{Reajuste y equilibrio del ordenamiento jurídico}

El ordenamiento jurídico tiene una pretensión de plenitud -inseparable de los objetivos centrales del Estado de Derecho- y delimita el marco de regulación ocupado por las normas de Derecho objetivo que, con arreglo a los principios informadores (pp. 7 y 16 EMTPC.c. y art. 1.4 C.c.), agotan el sistema de fuentes que explica y determina su saturación. No puede haber espacios vacíos ni oquedades - constitutivos de las llamadas lagunas del Derecho- a los que no alcance el efecto-inundación que sugiere la imagen plástica de dicho sistema. Aunque el acudir a esta descripción didáctica es fácil, hay dificultades para concretar, con certeza excluyente toda duda razonable, si, en su momento, sólo ha existido imprevisión u olvido del legislador —que, por inadvertencia más o menos excusable, no ha cuidado de atender ese supuesto- o conciencia e intencionalidad inequívocas de marginarlo y abstenerse de su tratamiento jurídico. Dilucidación de que ha de hacerse cargo la ciencia del Derecho.

Este quehacer científico repara en fenómenos que surgen al margen o con olvido del Derecho, aunque su rigurosa consideración muestra lo provechoso y trascendente de la perspectiva jurídica de su análisis. El régimen de las relaciones colectivas de trabajo - debido a la constancia de una contestación conflictiva y a la exigencia de técnicas pacificadoras- ha justificado la formación, por parte de la ciencia del Derecho, de una teoría de la autonomía colectiva - similar a la autonomía contractual de las relaciones juridicoprivadas- y, con ese motivo, ha realzado la novedad y el valor del ordenamiento jurídico extraestatal que, merced al ejercicio de la misma, concurre con el Derecho del Estado en el ámbito territorial de su acción soberana (arts. 37.1 CE, 1.255 C.c. y 82.1 ET).

Otro fenómeno al que la ciencia del Derecho sigue atenta es el de las transformaciones de aquellas realidades sociales cuya sucesión y novedad ponen en trance de caducidad y obsolescencia muchos experimentos del legislador. El Derecho se aplica al calor de la objetividad cuya inmediación permite captar, sensorial o sicológicamente, las realidades de la vida (p. 10 EMTPC.c.). Si el legislador no ha mostrado suficiente previsión y cautela en la factura de una ley cuya generalidad debe asegurar, cabe que, andando el tiempo, su regulación resulte inadaptable a los estados de cosas que su autor no logró predecir y a cuyos temas no prestó, por hipótesis, la atención precisa para evitarlos o resolverlos en su caso. Tales normas no son bienes perecederos o inactuales que, al modo de los objetos consumibles, toleran una renovación incompatible con su carácter de generalidad. Rasgo que, en un 
principio, significa extensión del favor de la ley a una comunidad o sector de ella, cuya audiencia social reivindica tenaz y llamativamente la satisfacción del interés que la norma dice proteger. La generalidad también supone que esa protección es duradera, sin frustrarse prematuramente ni exponerse a cambios cuyo radicalismo desordene la vida social y enerve el vigor de la tutela jurídica que se ofrece con visos de seguridad y permanencia. La ciencia del Derecho proclama que, si el legislador no intuyó dichas transformaciones, la norma ha de usarse de modo divergente del hasta entonces estilado, para que, en lo posible, su utilidad y generalidad queden a salvo. La ciencia del Derecho acude al elemento historicoevolutivo de interpretación y procura que este criterio, de delicadísimo manejo, permita adecuar el mensaje flexible a circunstancias surgidas después de la promulgación de una norma (p. 13 EMTPC.c.) que, de lo contrario, fracasa y queda desprovista de su valor vital. De ahí que deba estarse fundamentalmente - sin sucumbir al canto de sirena de otras opciones interpretativas- a la fisonomía que entonces adquiere la ley, a causa del nuevo espíritu y finalidad que la distinguen (art. 3.1 C.c.). Una vez más, la ciencia jurídica traslada a las soluciones del Derecho positivo una inspiración que, sin pertenecerles desde sus orígenes, responde a la máxima de que la letra mata y el espíritu vivifica.

Cabe que, con menos frecuencia, un cambio de signo político obligue a desmontar un ordenamiento jurídico y a instituir e inaugurar otro que le sustituye. Experiencia que ocurre cuando un sistema de libertades políticas sucede a otro de corte autoritario, con independencia de su momento histórico, de la modernidad del mecanismo de reemplazo y del carácter del régimen abolido. La introducción y puesta a punto de ese ordenamiento requiere correcciones y ajustes que el legislador no puede introducir con celeridad mágica, ya que han de ser pausados y estar exentos de radicalismo inoportuno. El nuevo ordenamiento no puede abrir fuego con la derogación incondicional y abrasiva de todas las expresiones normativas del sistema anterior y, a fin de evitar los cuantiosos y graves problemas del miedo al vacío, debe salvar las que conserven su utilidad social para satisfacer los intereses generales en que reside el bien común. Un proceso de depuración tan sensible se expone al fracaso si no cuenta con el acompañamiento de la ciencia del Derecho que, así las cosas, aprecia los inconvenientes y/o ventajas de usar de una técnica maximalista y de otra conservadora o criticista — según lo indulgente de sus respectivas premisas - para elegir y aplicar la solución más razonable. La construcción y el manejo del concepto de inconstitucionalidad sobrevenida (DD $3 \mathrm{CE}$ ) o, por mejor decir, de reajuste constitucional de las normas previgentes a la carta política, muestran una de las adquisiciones debidas a este esfuerzo científico. 


\section{Sensibilidad del Derecho positivo al influjo de la ciencia del Derecho}

La ciencia del Derecho - ligada a las consignas de la honestidad del espíritu crítico- denuncia y supera las tentaciones de dejar irresueltos los problemas jurídicos, ante la enojosa perspectiva de entregarse, en actitud devota y responsable, a su análisis y dilucidación. Sin poner en cuestión, ni mucho menos, lo progresivo y necesario del uso equitativo del Derecho, la invocación de la equidad encubre, muchas veces, la pereza y laxitud intelectuales con que se rehúyen las dificultades de forjar un discurso de calidad. No faltan incentivos para que el jurista logre salvar estos reparos. Gracias a los apoyos de la ciencia del Derecho, la legalidad dispone de recursos que las van disipando. Los jueces ordinarios trabajan sobre un ordenamiento jurídico completo y exento de lagunas, cuya saturación o plenitud impide pretextar que la dificultad del raciocinio hace insoluble la decisión del asunto que se les confía (art. 1.7 C.c.). Si la ley es oscura, su sentido se aclara con la interpretación (art. 3.2 C.c), si guarda silencio, como fuente primaria, debe irse en busca y escucharse la voz de las fuentes secundarias (art. 1.1 a 3 C.c.), y, si es insuficiente, la laguna que ofrece se colma por medio de una operación integradora (art. 4.1 C.c.). Precisiones a que llega la legislación con el auxilio de la ciencia del Derecho y no por cuenta propia. La ley dota de incentivos jurídicos que mitigan la frustración y el desaliento de los especialistas a quienes el signo deontológico del Derecho no brinda estímulos bastantes para reflexionar con delectación y con éxito. La efectividad de la tutela judicial (art. 24.1 CE) significa que los jueces han de pronunciar decisiones de fondo - cuya preferencia proscribe la tentación de escudarse en reparos de forma que las van demorando- y, en su caso, desestimar, si son fraudulentas o abusivas, las pretensiones sometidas a su conocimiento (arts. 11.2 LOPJ y 25.1 LPL).

La legalidad que, gracias a estos arbitrios, facilita la aplicación del Derecho y reduce a sus debidas dimensiones el alcance de las formas, no los asume si antes la ciencia del Derecho no los ha elaborado con una pulcritud y calidad dogmática cuya fuerza de convicción intelectual les dota del crédito exigible para que se acepte su contribución. Cuantas veces surgen novedades, el legislador se sincera y no desdeña la oportunidad de hacer la consideración - escrita en los preámbulos que informan de la necesidad de la innovación, del modo en que se ha practicado y de su fisonomía general- de que, en buena parte, el ordenamiento jurídico recibe e incorpora los hallazgos que la ciencia del Derecho incluye entre sus adquisiciones más recientes y pone a su disposición. Es muy feliz la fórmula de que, en tales casos, se recogen las enseñanzas y respuestas de la doctrina a las dudas suscitadas por la práctica (B. 1. ${ }^{\text {BC.c.). }}$ 


\section{EFICIENCIA CONSTRUCTIVA DE LA CIENCIA DEL DERECHO}

\section{Influencia de la ciencia del Derecho en la formación del ordenamiento jurídico}

Cuando la norma jurídica es clara, los obstáculos a su aplicación satisfactoria pueden venir de la hostilidad o negativa de las personas o comunidades a que se dirigen sus mandatos o prohibiciones, de la imposibilidad de probar el supuesto de hecho que condiciona su eficacia y de la desatención nacida de la decadencia o el desuso. El principio de que las leyes sólo se derogan formalmente por otras posteriores (art. 2.2 C.c.) y la omisión de referencias descalificadoras a la ineficacia del desuso o la práctica en contrario (viejo art. 5 C.c.) explican cómo esta causa de desvitalización llega a desvirtuar la vigencia y obligatoriedad de una norma no expulsada del ordenamiento jurídico y que en Derecho sigue viva. Por accesible y simple que parezca la versión expresiva de una norma jurídica, siempre hay que acomodar a los cambios históricos - que han de encajar en la proposición constitutiva del supuesto de hecho- el mensaje que guarda y quiere transmitir. Los llamados a declarar las consecuencias perseguidas por el ordenamiento, casi nunca pueden actuar y conducirse como resonadores inertes de la ley. Su discurso introduce - automática e inevitablemente- reflexiones de acompañamiento que son imprescindibles para un examen individualizado del problema. Dan de lado al prejuicio simplista de que el juez - aplicador por excelencia del Derechosólo es, como rezaba ingenuamente la fórmula mecanicista del principio de separación de poderes, el eco que se limita a repetir las palabras de la ley o el agente de unas operaciones silogísticas cuya suficiencia lógica garantiza una solución convincente. La operación de aplicar la que, a primera vista, puede parecer la norma jurídica más modesta y exenta de dificultades, conserva la atracción del experimento que acredita el arte de transformar el Derecho en justicia.

Si la proposición de una norma jurídica encierra dificultad de entendimiento, su aplicación — compuesta de la subsunción del hecho en el tipo o imagen rectora, y de la declaración del efecto jurídico subsiguiente a la verificación de su encaje correcto- es inviable sin antes haberse esclarecido el sentido y alcance de su formulación, reduciendo sus términos a los propios de un juicio inteligible. Acomodar la situación histórica concreta al supuesto de hecho resulta imposible si la incomprensión del lenguaje de la norma impide esa operación de acercamiento e inutiliza el esfuerzo de ajuste. Las razones de la dificultad dependen del signo de los tiempos y, a su ritmo y compás, se suceden y se multiplican. El viejo legislador elaboraba leyes que, salvo excepciones, se comprendían fácil- 
mente y cumplían una finalidad didáctica que se justificaba por el crédito doctrinal de los especialistas encargados de hacerlas y de los mediadores, que, en el proceso parlamentario, perfeccionaban su factura. El peso de esta responsabilidad gravitaba sobre juristas eminentes, que dieron su nombre a las obras legislativas a que se les confiaban. La brillantez de los preámbulos no dejaba de aludir a la necesidad social que había llamado la atención del legislador, reseñaba la calidad e importancia de los trabajos precedentes, detallaba los materiales de su elaboración, concretaba la variedad de las aportaciones útiles y, pese a la excelencia de ese empeño, mantenía viva su preocupación ante problemas no resueltos o eventualmente derivados de las soluciones obtenidas entonces. Gracias a la dignidad y precisión del lenguaje utilizado, el entendimiento de las normas jurídicas se facilitaba y se disipaban las dificultades de su aplicación en el futuro. Prevalecía la confianza en el propósito de minimizar los problemas interpretativos derivados de ello y — quizá con exceso de optimismo- se aspiraba a hacer de las leyes instrumentos indefinidamente provechosos. El peso específico de las ideologías era menos sensible, porque se compartía la conciencia — nada particularizada ni sectariade las aspiraciones centrales de la sociedad y de los postulados del progreso. Se coincidía en la determinación de resolverlos al margen de la querencia que hoy responde al rótulo, fácil y temible, de voluntad políti$c a$. Aun quedaba demasiado cerca el influjo del idealismo racionalista $\mathrm{y}$, a causa de ello, subsistía una postura de respeto con cuantas novedades legislativas decían, más o menos explícitamente, acarrear los materiales de su depósito e inspirarse en sus proclamaciones.

La perspectiva de la actual situación es diferente. Los redactores materiales de las leyes no suelen ser juristas avezados a las peripecias del arte de legislar, sino gabinetes de expertos o equipos de asesores para el caso - cuando no personas físicas tan hueras de prestigio científico como dóciles a las consignas impartidas - que no ocultan su precipitación por terminar el encargo que se les encomienda. El resultado del trabajo de producción legislativa da a la luz unos textos legales en los que el espíritu de consenso - a costa, demasiadas veces, de sacrificar, sin tasa ni morigeración, bienes indisponibles y valiosos-y el transaccionalismo van dejando su huella. La supresión de las introducciones - que, durante algún tiempo, dejaron de preceder al texto de las leyes y que después han resurgido- parece responder a la idea de que su subsistencia es inútil y contraproducente. Al informar con exactitud y detalle del propósito del legislador, crean un riesgo de petrificación y entorpecen o frenan la soltura con que la creatividad interpretativa puede sustituir su voluntad por la de la norma jurídica que, a su tiempo, siente el impacto y reacciona ante el reto de las realidades sociales (art. 3.1 C.c.). Los preámbulos sue- 
len aventurar interpretaciones constitucionales que el legislador ordinario - consciente de lo provechoso de las valoraciones preventivas de este signo - no duda en emprender para evitar la inconstitucionalidad de las leyes a que se refieren. Muchas más leyes de las que sería de desear, provienen de consignas ideológicas que, escudadas en la ventaja numeral de la mayoría parlamentaria, rechazan obstinadamente las aportaciones y mejoras de otra procedencia e incurren en un incontrolable y craso abuso de la potestad legislativa (art. 67.2 CE). El moderno concepto de voluntarismo normativo — contrapuesto a las orientaciones intelectualistas y enarbolado por los epígonos de la voluntad política o el decisionismo de este nombre- ha imperado, durante algún tiempo, y ha ganado incluso la batalla en pro de un tipo de legislación devaluada y/o sectaria, o, si se prefiere, de un modelo o estilo - nunca un arte-de legislador, cuyas peripecias no merecerán, a buen seguro, el encomio de los juristas y politólogos que el futuro vayan a enjuiciarlas.

\section{Corresponsabilidad interpretativa de la ciencia del Derecho}

Los problemas de interpretación —que, en otras circunstancias, son menos frecuentes - se acrecientan con una legislación de este carácter. Cierto que, en razón directa de la proliferación de las cuestiones interpretativas, se accede a medios más modernos y expeditivos para disolverlas. El legislador puede trazar, como una novedad plausible, orientaciones hermenéuticas a cuya introducción se dedican, según los pareceres, elogios y reparos (p. 13 EMTPC.c.). Llega el momento en que los jueces ordinarios experimentan la necesidad de manejar — pues a ello están urgidos (arts. 5.1 y 7.1 LOPJ) los principios y preceptos constitucionales como elementos contextuales de interpretación que son comunes a todos los sectores del ordenamiento jurídico, de los que indistintamente se predicen. También el Derecho de las relaciones colectivas de trabajo se aplica a través de unas sentencias meramente interpretativas - llamadas, por ello, normativas - que emanan de los órganos jurisdiccionales (arts. 151.1 y 158.2 LPL). Ello da idea de la complejidad y magnitud que, en los procelosos mares de la aplicación del Derecho objetivo, va adquiriendo el cometido del intérprete.

La interpretación fue, en sus principios, un mensaje encargado de simplificar y traducir situaciones confusas o míticas. El Derecho no escapa, pese a su pretensión de claridad, a la exigencia de un entendimiento que cada vez se adhiere más a las interpretaciones sucesivamente impuestas por las cambiantes realidades sociales que, al transformar el tenor de sus proposiciones, mudan también el signo de sus prohibiciones y mandatos. 
La interpretación de las normas jurídicas es una tarea compartida por el quehacer de los órganos judiciales y los aciertos de la doctrina científica. El transcurso del tiempo y el aprecio sereno de las cosas han aclarado cómo, superados los antagonismos y prejuicios clasistas, esas acciones interpretativas se entrecruzan y enriquecen considerablemente. Lo acuciante de tantos problemas, las experiencias de una judicialización que pone al descubierto flancos indefensos, multiplica sus pormenores y suma otros matices a la sencillez de sus planteamientos, de origen, la necesidad de utilizar categorías científicas de alguna sutileza para enfrentarse a cuestiones de primera magnitud, configuran un estado de corresponsabilidad interpretativa. La doctrina y los órganos jurisdiccionales coinciden, más o menos expresamente, en que esta actitud de recíproco auxilio no sólo es obligada para salvar nuevas y varias exigencias tecnicojurídicas, pues lo contrario constituye un ejemplo deplorable y un atentado contra la dignidad de la causa del Derecho. Los juristas prácticos y en especial el cuerpo judicial, no pueden hacer a la doctrina el reproche - de que, tiempo atrás, se echó mano abusiva e indelicadamente- de que su acervo de sabiduría no se ha curtido en lides y experiencias jurídicas de calado bastante para emprender una obra recia de transformación. Tampoco la doctrina puede censurar a los jueces - asediados por problemas de reconocida y creciente dificultad- su acantonamiento en posiciones trasnochadas o su inflexible adhesión a fórmulas pasadas de moda, pues la complejidad de las incógnitas que han de afrontar hoy día, les obligan a análisis en que la fatiga del discurso y la ponderación intelectual — siempre ayudados por la contribución de la doctrina- son inherentes a la satisfacción del derecho fundamental a la efectiva tutela judicial (art. 24.1 CE). Alejan la figura del juez de la definición simplista del oráculo que sólo reitera las palabras de la ley, cuando, en rigor, continuamente las reanima e inscribe en un mensaje que ha de reunir los valores de la persuasión y la creatividad.

\section{Interacciones del pensamiento judicial y la ciencia del Derecho}

Las dimensiones que adquiere la construcción de cierta literatura jurídica reflejan el cambio producido. Va generalizándose, a semejanza de los países anglosajones, el cultivo del género literario que consiste en comentar y difundir las resoluciones judiciales en beneficio de la interpretación. Cosa distinta es el nivel de calidad que este género ofrece. La doctrina opera sobre dichos pasajes en régimen de vigilancia permanente y en ejercicio crítico de su capacidad de censurar las soluciones que 
adoptan. Los jueces - sujetos a un control cuyo provecho reconocendedican atención especial al rigor de sus razonamientos y cuidan, con detención y esmero, de la forma y la sustancia sus decisiones. Esta obra de cooperación inconsciente mejora las técnicas de aplicación del Derecho y enriquece a las dos comunidades de juristas, la judicial y la científica. De ahí que la doctrina y la jurisprudencia dejen de ser conceptos o situaciones antagónicas, y que sus agentes acepten esta cohabitación, no bajo el resignado lema de estar obligados a entenderse, sino convencidos del progreso y la utilidad que se siguen de una interacción tan fructífera.

Pudo pensarse ingenuamente que, en esa concurrencia, la doctrina judicial iba a primar — ganando la batalla - sobre las aportaciones de la doctrina científica, al contar con el imperium de su carácter oficial y con la coactividad que hace posible el cumplimiento de las sentencias judiciales. El valor de las aportaciones doctrinales sólo resultaría de su intensa razonabilidad y de su poder de sugestión intelectual. Su correlación determina que, hoy por hoy, la actividad judicial nunca pierde de vista — pues no puede permitirse tamaña licencia- las más valiosas construcciones del pensamiento jurídico especulativo, de cuya asistencia necesita indefectiblemente. La doctrina cuenta siempre con las experiencias - resultantes de los conflictos de intereses (p. 10 EMTPC.c.) y no de hipótesis de trabajo simuladas o ficticias- que se someten al conocimiento de la jurisdicción y cuyos rasgos históricos individualizan las causas de pedir de las acciones y excepciones que entonces se deducen.

Las interpretaciones doctrinal y judicial se encaran a sus respectivas tareas en condiciones que, aunque inicialmente han diferido, se asimilan y acercan con el tiempo. La doctrina comienza planteándose los problemas interpretativos a partir de ciertas hipótesis de aplicación de las normas jurídicas que las experiencias y el futuro se encargan de ratificar o desdecir. Parte de su ejercicio, en estas condiciones, puede ser una inversión improductiva y frustrada, si, a la larga, no se confirman la entidad y consistencia del tema a cuyo descubrimiento y solución se ha dedicado la interpretación. Los órganos judiciales la emprenden a causa del debate sobre el bien de vida que ante ellos se discute. El tiempo atenúa lo divergente y distante de ambas interpretaciones. La doctrina se entrega al análisis de problemas concretos que surgen en los ámbitos extrajudiciales o se llevan ante los jueces ordinarios. Deja de especular —más o menos creativamente - sobre los aspectos de la aplicación de la norma y concentra su esfuerzo en el examen de las experiencias que arrojan sus episodios conflictivos. Los órganos jurisdiccionales sitúan los problemas de interpretación en el plano de generalidad que resulta de ir acumulando los matices interpretativos y multiplicando las experiencias adquiridas. 
Ello obliga a enfoques que, aun sin riesgo de abstracción excesiva, adiestran y acostumbran al uso de perspectivas generales, y transmiten a la práctica judicial un reflejo academicista e ilustrado. Inclinación que no puede censurarse en nombre de una austeridad especulativa que disimula la escasez de una reflexión suficientemente persuasiva, e incluso se resiente de las más graves taras del pensamiento débil.

\section{Abreviaturas y siglas}

art. artículo

C.c. $\quad$ Código Civil español de 24.7. (8) 89

CE Constitución española de 27-12-78

EMTPC.c. Exposición de Motivos de la L. 31-5-74, de reforma del Título Preliminar del Código Civil

ET Estatuto de los Trabajadores (Real Decreto Legislativo de 24-3-95)

LOPJ Ley Orgánica del Poder Judicial de 1-7-85

PL Ley del Procedimiento Laboral (Real Decreto Legislativo de 7-4-95)

p. parágrafo 